\title{
Mini-Review on Influence of Biochar for Sustainable Agriculture
}

\author{
Meththika Vithanage*, Viraj Gunarathne and Tharanga Bandara
}

\begin{abstract}
Soil quality degradation is one of the most widespread phenomena for declining agricultural productivity throughout the world. It has been estimated that more than $40 \%$ of agricultural lands have been already become marginal due to mismanagement of soil. Biochar is a carbon rich product of a thermochemical conversion of biomass to be recognized as a beneficial soil amendment. It is not a novel soil amendment and history goes back to Mayan civilization called "Terra preta" soil. Due to the high fertility of these Amazon basin soils, many researchers in the world were interested in properties and application of biochar. This review gives an overview of agricultural benefits of biochar as a soil amendment. However, still there are many pros and cons of the application of biochar and this article will highlight the importance of further researches on the application of biochar as a soil amendment.
\end{abstract}

Keywords: Agricultural benefit, Biochar, Nutrient dynamic, Soil degradation

\section{INTRODUCTION}

Soil plays a crucial role in sustaining life on earth. However, in the last few decades, poor soil quality has become a frequent title leading to many discussions. It has been reported that in the past five decades, about 2 billion hectares of agricultural lands, permanent pastures, woodlands and forests have been degraded (Arshad and Martin, 2002).

Environmental Chemodynamics Research Group, National Institute of Fundamental Studies, Kandy, Sri Lanka

*meththikavithanage@gmail.com
It has further been estimated that nearly $40 \%$ of the world agricultural lands have turned into unproductive due to poor soil quality, as a result of soil erosion, atmospheric pollution, extensive soil cultivation, over-grazing, land clearing, salinization, and desertification (Doran and Zeiss, 2000). Global annual loss of soil from water and wind erosion of agricultural lands has been estimated as more than 70 billion metric tons (Awad et al., 2013). However, the importance of maintaining soil quality for sustainable agriculture has been described by several authors in their studies (Arshad and Martin, 2002).

To maintain soil quality for sustainable agriculture and restoration of degraded soil are the biggest challenges in the modern agricultural world. Biochar is considered as one of the better options to restore soil properties in a sustainable manner due to its universal potential of being a material which can sequestrate carbon, act as a fertilizer and as an amendment for degraded soils. Mayan civilization is one of the best examples for improving soil quality by using biochar (Lehmann et al., 2011). Among soils in central Amazonia, Terra Preta is the most fertile soil with higher nutrient levels and a better nutrient retention capacity than surrounding infertile soils due to the application of biochar. Later, this discovery led many researchers to be interested in the study of biochar and its applications for soil quality improvement.

Biochar is a carbon rich product, produced by thermal decomposition of various organic materials under limited oxygen environment (Lehmann et al., 2011; Houben et al., 2013). The pyrolysis product is highly aromatic and has increased carbon 
stability relative to original feedstock materials. The proportion of aromatic structure in biochar is comparatively high, and the condensed aromatic structure shows further resistance against decomposition (Lehmann et al., 2011).

Biochar can be produced by any type of organic biomass from agriculture residue, forest residue, invasive plants and even from municipal solid waste. The conversion of waste products into biochar is being considered as one of the best methods to manage the solid wastes. Several other agricultural wastes such as bagasse, wood waste, bamboo, rapeseed and coconut shell are also used in biochar production (Houben et al., 2013; Oleszczuk et al., 2013). Figure 1 depicts the overall agricultural benefit of biochar application.

However, according to the research conducted in last decade, biochar seems to be a massive view, yet there are many serious concerns surrounding it. Compared to the other amendments, biochar addition to soil is virtually irreversible and it persists more than a thousand years in the soil system. At the same time, some biochars such as rice husk biochar may release toxic elements and compounds to the environment which may act as potential toxins for plants and microbes. Application rate may be another concern since higher application rates may create toxicity to plants as well as soil biota. Therefore, it is important that we have an inclusive understanding of how biochar interacts with soil in the long term before the wide-scale application.

\section{BIOCHAR ON SOIL CHEMICAL AND PHYSICAL PROPERTIES}

The soil chemical and physical properties are mainly changing with the properties of biochar. Therefore, understanding of the properties of biochar is very imperative.
The characteristics of biochar is influenced by the pyrolysis condition and the feedstock, which is used in its production (Sohi et al., 2010). Biochar additions cause changes in soil $\mathrm{pH}$, electrical conductivity (EC), cation exchange capacity (CEC), soil organic carbon (SOC) and nutrient level in the soil (Jien and Wang, 2013).

The increase in soil $\mathrm{pH}$ following biochar addition has been described well. Pyrolysis temperature is another important factor that determined the $\mathrm{pH}$ of biochar. Generally $\mathrm{pH}$ increases with increasing pyrolysis temperature and it is mainly due to separating of alkali salts from organic materials and loss of acidic functional groups at high pyrolysis temperature (AlWabel et al., 2013). The biochar-amended weathered soil showed an increase in the CEC by significantly increasing the exchangeable $\mathrm{K}, \mathrm{Ca}$, and $\mathrm{Mg}$ contents in the soil (Al-Wabel et al., 2013). The scales of changes were approximately proportional to the rate of biochar application rates.

The physical properties of soil are inherent property that determined by the nature of the soil mineralogy and organic matter content. Application of biochar to the soil matrix contribute to the sever changing of the physical nature of the soil, including texture, structure, depth, bulk density, pore size distribution and hydraulic properties (Lehmann and Joseph, 2009).

The biochar application rate significantly controls the many physical properties of the soil system. Soil saturated hydraulic conductivity considered as a function of soil texture, soil particle packing, clay content, organic matter content, soil aggregation, bioturbation, shrink-swelling, and overall soil structure (Lehmann and Joseph, 2009). Biochar application is also capable to improve the 


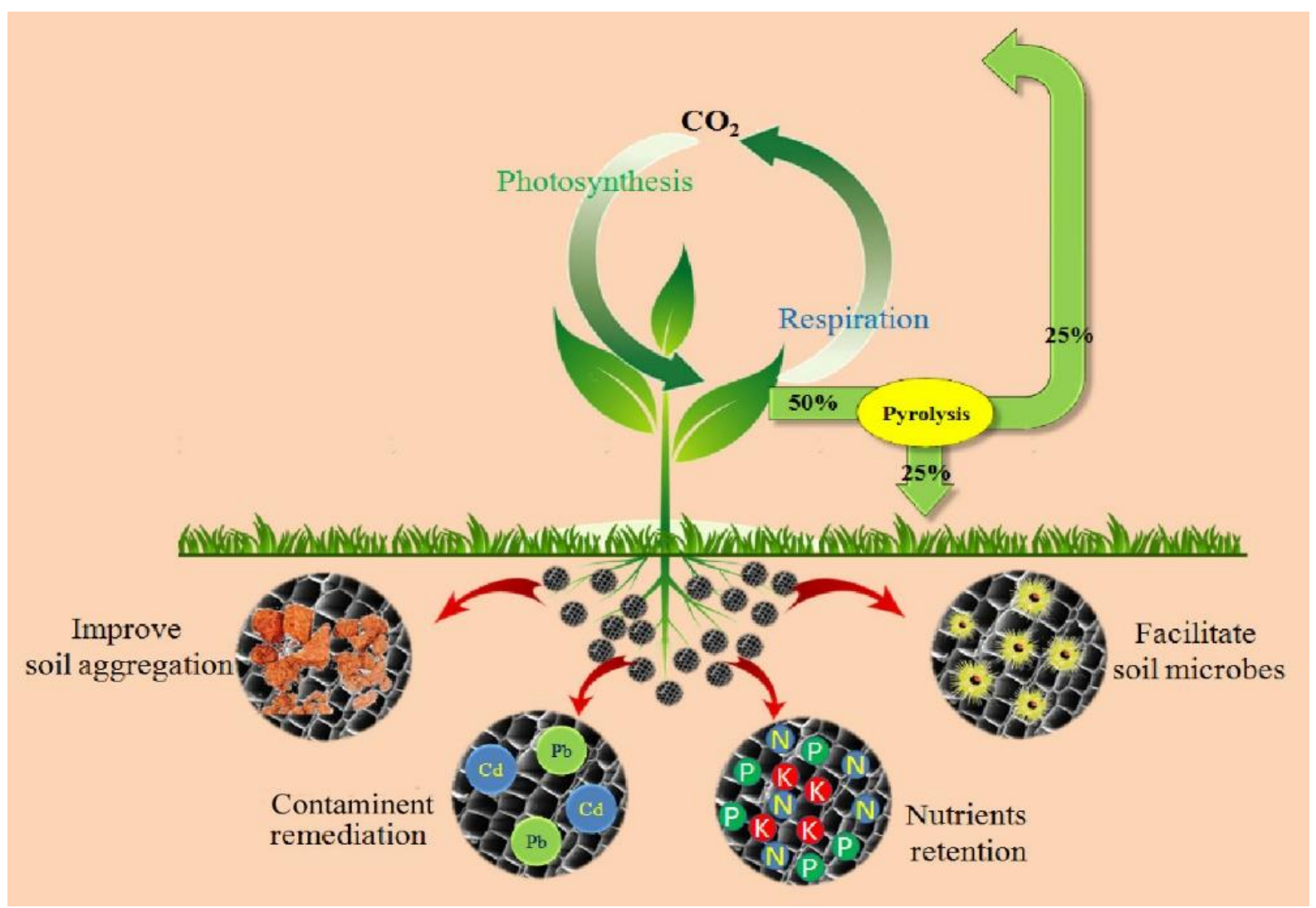

Figure 1: Overall agricultural benefits of biochar

saturated hydraulic conductivity of the top soil (Asai et al., 2009).

Increasing biochar concentration significantly decreases saturated hydraulic conductivity, bulk density and soil water repellency while increasing soil water retention (Devereux et al., 2012). Biochar is highly porous, thus its application to soil is considered to improve a range of soil physical properties including total porosity, pore size distribution, soil density, soil moisture content, water holding capacity or plant available water content and hydraulic conductivity of the soil. However, accurate identification of amendment rates for a particular purpose is needed.

\section{BIOCHAR ON NUTRIENTS DYNAMIC IN SOIL}

Sustainable soil ecosystem needs regular recycling of nutrients to maintain proper flora and fauna diversity. The application of biochar to the soil system affects the regular recycling of nutrients in a different way and the knowledge of these soil nutrient transformations is very important.

The addition of biochar in soil can induce either a positive or negative priming effect on native soil $C$ which may either reduce or enhance the $C$ storage potential of biochar (Wang et al., 2013). The priming effect defined as a change in the mineralization rates of soil organic carbon (SOC) by soil treatments (Wang et al., 2013). Soil microbial community and C 
availability simultaneously control SOC decomposition (Wang et al., 2003) and therefore the addition of biochar induce priming effects on soil C mineralization ( $\mathrm{Lu}$ and Zhang, 2015). However, still there are contrasting data reported on the priming effects on soil $\mathrm{C}$ mineralization in the presence of biochar. Luo et al.. (2011) demonstrated the true positive priming effect by biochar on native soil organic C. Many studies reported that application of biochar attributes to increase retention of most of the nutrients within a root zone (Laird et al., 2010; Yao et al., 2012; Zheng et al., 2013). Application of biochar to the subtropical cropland soil has the potential for reducing $\mathrm{N}$ leaching due to both improved $\mathrm{N}$ adsorption and increased unaccounted $\mathrm{N}$ (Clough et al., 2013). Biochar carries potential P fertilizer value (Nelson et al., 2011). The effect of biochar on soil $\mathrm{P}$ mainly determined by their chemical composition and surface characteristics (Nelson et al., 2011). In general, increased $\mathrm{P}$ availability with biochar addition into the soil, determined by the increased soil $\mathrm{pH}$ and direct release of $\mathrm{P}$ from biochar (Xu et al., 2013).

\section{SOIL BIOLOGICAL ACTIVITIES}

\section{Biochar Alter Soil Microbial Abundance and Diversity}

Soil microorganisms are the key for a sustainable soil ecosystem. Microbial diversity and abundance are two important factors that determine healthy soil system. The porous structure of biochar empowers a high water holding capacity and increases the surface area, leading to a higher sorption of dissolved organic molecules and serving as habitat for soil microorganism (Ladygina and Rineau, 2013). Further, the chemical changes in the soil due to biochar addition may initially enhance soil microbial activity and a positive priming effect on organic matter decomposition.

Biochar amendment resulted in significant shifts in both bacterial and fungal taxa (Lehmann et al., 2011). Addition of fast pyrolysis woody biochar in large quantities changed the microbial community composition towards a more gram-negative bacteria dominated community and improved soil fertility without adverse effects on soil biota in temperate soils (Ding et al., 2013). The application of pyrogenic carbon as a soil amendment had a prominent impact on the structure and metabolic activity of the soil microbial communities. Khodadad et al., (2011) observed that unburned forest soils with no history of destined burning exhibited lower microbial numbers and diversity in response to addition of low temperature biochars. Further, burned and unburned both soil types were positively impacted by higher temperature biochars and exhibited an increase in microbial number and diversity.

Nutrient recycling is one of the major functions in the microbes presence of the soil ecosystem. Therefore, it is suggested that the use of biochar as a soil management practice should take into account not only changes to the soil's physiochemical properties, but its biological properties as well (Ducey et al., 2013). Moreover, the application of hightemperature produced biochar enhanced microbial nitrous oxide reduction and increased the abundance of microorganisms capable of $\mathrm{N}_{2}$-fixation (Cayuela et al., 2013; Clough et al., 2013; Zheng et al., 2013).

\section{Biochar and Soil Micorrhizal Fungi}

Although many studies reported an increase in plant yield with the application of biochar, knowledge on interactions between biochar and plant growth 
promoting microbes, such as mycorrhizal fungi is lacking. (Lecroy et al., 2013; Rillig et al., 2010). A recent study revealed that the slow pyrolysis biochar with high surface area had a highest fungi colonization (Lecroy et al., 2013; Rillig et al., 2010). Four mechanisms have been suggested to explain the micorrhizal fungi and biochar interaction (Warnock et al., 2007):
1. Biochar changes soil nutrient availability

2. Biochar alters the activity of other microorganisms that have effects on mycorrhizae,

3. Biochar alters the signaling dynamics between plants and mycorrhizal fungi or detoxifies allelochemicals,

4. Biochar serves as a refuge for colonizing fungi and bacteria

\section{Biochar and Soil Enzymes}

Since biochars have been shown to possess a high sorptive affinity due to porous structure and high surface area biochar might sorbs both the organic chemicals added as artificial substrates and the products in soil enzyme assays (Swaine et al., 2013). The activities of soil enzymes are highly variable with soil type and depth, cropping season and type, management strategy, amendments etc assays (Varma and Das, 2011). A study conducted recently reported that some extracellular enzyme activities were stabilized by the biochar addition but it is dependent with the biochar addition rate and the type of the enzyme while certain extracellular enzyme activities were reduced (Elzobair, 2013). Yet the effect on soil enzymes is not understood well enough. Long-term evaluation of soil enzymatic activities with biochar application is important than the short-term assay.

\section{Biochar and Plant Growth}

Biochar act as a soil conditioner enhancing plant growth by mobilizing and immobilizing plant nutrients (Lehmann et al., 2006). Carbon is one of the major nutrients that determine the growth of plants. Significant increases in plant growth and yield mostly have been reported when biochar was applied to tropical and subtropical soils . Furthermore, biochar has been generally used in conventional arable soils for improving soil fertility. Moreover, no evidence exists so far for direct negative effects of biochars on plant roots (Lehmann et al., 2011; Andrew et al., 2013). However, not all biochars comprise the same properties.

Application of wheat straw biochar can improve wheat yield, positive effect on seed germination and increased soil available phosphate (Alburquerque et al., 2013). The pyrolysing temperature is the key factor that determines the most of the characteristic features of biochar (Lehmann and Joseph, 2009).

Acidified soil amelioration with biochar can increase crop yield through improving soil chemical conditions and changing the availability of nutrients (Lai et al., 2013, Zhang et al., 2012). Biochar addition to mineral fertilizer significantly increased plant growth compared to mineral fertilizer alone (Deenik et al., 2009). Hence, there is an urgent necessity to recover soil quality by introducing sustainable land-use practices and/or amendments for the purpose of reducing the rate of soil degradation, improve fertility and to maintain long-term sustainability of the plantation system (Li et al., 2012). 


\section{FUTURE OUTLOOK}

Most of the biochar addition increase soil $\mathrm{pH}, \mathrm{CEC}, \mathrm{EC}$ and nutrient retention. However, these properties vary with feedstock as well as production temperature and application rate. Therefore, there is a high risk in addition of biochar into the alkaline soil. In tropical belt, most of the soils are highly weathered and considered as infertile soil. When managing tropical soil, biochar plays a significant role to improve soil quality. Soil microbes and enzymes are considered as primary indicators of soil quality and biochar alter soil microbial community composition and diversity. Nevertheless, still there is doubt about the effect of biochar on soil enzymatic activities. Therefore, future research is needed for identifying the mechanism of interaction of biochar versus enzymes. Most of the agronomic research implies that biochar application improves crop productivity. However, there is little evidence on biochar effect on crop growth in the temperate and tropical region. Yet the long term studies are not adequate hence, more studies are needed in terms of lengthy periods. At the same time, multidisciplinary and multi-parametric studies such as soil physics, chemistry and biology should be encouraged so that the assessment of whole soil can be drawn better compared to segmented studies.

\section{REFERENCES}

Al-Wabel, M. I., Al-Omran, A., El-Naggar, A. H., Nadeem, M. and Usman, A. R. A. (2013). Pyrolysis temperature induced changes in characteristics and chemical composition of biochar produced from conocarpus wastes. Bioresource Technology, 131, 374-379.
Alburquerque, J. A., Salazar, P., Barrón, V., Torrent, J., Del Campillo, M. D. C., Gallardo, A. and Villar, R. (2013). Enhanced wheat yield by biochar addition under different mineral fertilization levels. Agronomy for sustainable development, 33, 475484.

Andrew, C.-D., Samuel, A., Simon, J. and Margaret, S. T. (2013). Heterogeneous global crop yield response to biochar: a metaregression analysis. Environmental Research Letters, 8, 044049.

Arshad, M. A. and Martin, S. (2002). Identifying critical limits for soil quality indicators in agroecosystems. Agriculture, Ecosystems and Environment, 88, 153-160.

Asai, H., Samson, B. K., Stephan, H. M., Songyikhangsuthor, K., Homma, K., Kiyono, Y., Inoue, Y., Shiraiwa, T. and Horie, T. (2009). Biochar amendment techniques for upland rice production in Northern Laos: 1. Soil physical properties, leaf SPAD and grain yield. Field Crops Research, 111, 81-84.

Awad, Y., Blagodatskaya, E., Ok, Y. and Kuzyakov, Y. (2013). Effects of polyacrylamide, biopolymer and biochar on the decomposition of 14C-labelled maize residues and on their stabilization in soil aggregates. European journal of soil science, 64, 488-499.

Cayuela, M. L., Sánchez-Monedero, M. A., Roig, A., Hanley, K., Enders, A. and Lehmann, J. (2013). Biochar and denitrification in soils: when, how much and why does biochar reduce $\mathrm{N}_{2} \mathrm{O}$ emissions? Scientific Reports, 3, 1732.

Clough, T. J., Condron, L. M., Kammann, C. and Müller, C. (2013). A review 
of biochar and soil nitrogen dynamics. Agronomy, 3, 275-293.

Deenik, J. L., Mcclellan, A. and Uehara, G. Year. Biochar volatile matter content effects on plant growth and nitrogen transformations in a tropical soil. In: Western nutrient management conference, (2009). 26-31.

Devereux, R. C., Sturrock, C. J. and Mooney, S. J. (2012). The effects of biochar on soil physical properties and winter wheat growth. Earth and Environmental Science Transactions of the Royal Society of Edinburgh, 103, 13-18.

Ding, Y.L., Liu, J. and Wang, Y. Y., (2013). Effects of biochar on microbial ecology in agriculture soil: a review. The Journal of Applied Ecology, 24, 3311-7.

Doran, J. W. and Zeiss, M. R. (2000). Soil health and sustainability: managing the biotic component of soil quality. Applied Soil Ecology, 15, 3-11.

Ducey, T. F., Ippolito, J. A., Cantrell, K. B., Novak, J. M. and Lentz, R. D. (2013). Addition of activated switchgrass biochar to an aridic subsoil increases microbial nitrogen cycling gene abundances. Applied Soil Ecology, 65, 65-72.

Elzobair, K. (2013). Biochar effects on soil microbial communities and resistance of enzymes to stress. MSc Thesis, Colorado State University.

Houben, D., Evrard, L. and Sonnet, P. (2013). Beneficial effects of biochar application to contaminated soils on the bioavailability of $\mathrm{Cd}, \mathrm{Pb}$ and $\mathrm{Zn}$ and the biomass production of rapeseed (Brassica napus L.). Biomass and Bioenergy, 57, 196204.

Jien, S.-H. and Wang, C.-S. (2013). Effects of biochar on soil properties and erosion potential in a highly weathered soil. Catena, 110, 225233.

Khodadad, C. L., Zimmerman, A. R., Green, S. J., Uthandi, S. and Foster, J. S. (2011). Taxa-specific changes in soil microbial community composition induced by pyrogenic carbon amendments. Soil Biology and Biochemistry, 43, 385-392.

Ladygina, N. and Rineau, F. (2013). Biochar and soil biota, CRC Press.

Lai, W.-Y., Lai, C.-M., Ke, G.-R., Chung, R.-S., Chen, C.-T., Cheng, C.-H., Pai, C.-W., Chen, S.-Y. and Chen, C.-C. (2013). The effects of woodchip biochar application on crop yield, carbon sequestration and greenhouse gas emissions from soils planted with rice or leaf beet. Journal of the Taiwan Institute of Chemical Engineers, 44, 10391044.

Laird, D., Fleming, P., Wang, B., Horton, R. and Karlen, D. (2010). Biochar impact on nutrient leaching from a Midwestern agricultural soil. Geoderma, 158, 436-442.

Lecroy, C., Masiello, C. A., Rudgers, J. A., Hockaday, W. C. and Silberg, J. J. (2013). Nitrogen, biochar, and mycorrhizae: Alteration of the symbiosis and oxidation of the char surface. Soil Biology and Biochemistry, 58, 248-254.

Lehmann, J., Gaunt, J. and Rondon, M. (2006). Biochar sequestration in terrestrial ecosystems-a review. Mitigation and adaptation strategies for global change, 11, 395-419.

Lehmann, J. and Joseph, S. (2009). Biochar for Environmental Management. Science and Technology. Edited by UK, Earthscan. 
Lehmann, J., Rillig, M. C., Thies, J., Masiello, C. A., Hockaday, W. C. and Crowley, D. (2011). Biochar effects on soil biota-a review. Soil Biology and Biochemistry, 43, 1812-1836.

Li, H., Ma, Y., Liu, W. and Liu, W. (2012). Soil changes induced by rubber and tea plantation establishment: comparison with tropical rain forest soil in Xishuangbanna, SW China. Environmental management, 50, 837-848.

Luo, Y., Durenkamp, M., De Nobili, M., Lin, Q. and Brookes, P. (2011). Short term soil priming effects and the mineralisation of biochar following its incorporation to soils of different $\mathrm{pH}$. Soil Biology and Biochemistry, 43, 2304-2314.

Nelson, N. O., Agudelo, S. C., Yuan, W. and Gan, J. (2011). Nitrogen and phosphorus availability in biocharamended soils. Soil Science, 176, 218-226.

Oleszczuk, P., Jośko, I. and Kuśmierz, M. (2013). Biochar properties regarding to contaminants content and ecotoxicological assessment. Journal of Hazardous Materials, 260, 375-382.

Rillig, M. C., Wagner, M., Salem, M., Antunes, P. M., George, C., Ramke, H.-G., Titirici, M.-M. and Antonietti, M. (2010). Material derived from hydrothermal carbonization: Effects on plant growth and arbuscular mycorrhiza. Applied Soil Ecology, 45, 238-242.

Sohi, S., Krull, E., Lopez-Capel, E. and Bol, R. (2010). A review of biochar and its use and function in soil. Advances in agronomy, 105, 47-82.

Swaine, M., Obrike, R., Clark, J. M. and Shaw, L. J. 2013. Biochar alteration of the sorption of substrates and products in soil enzyme assays. Applied and Environmental Soil Science, (2013).

Varma, A. and Das, S., K. (2011). Role of enzymes in maintaining soil health In: Soil Enzymology, Soil Biology, Springer, 25-42.

Wang, Q., Xiao, F., He, T. and Wang, S. (2013). Responses of labile soil organic carbon and enzyme activity in mineral soils to forest conversion in the subtropics. Annals of forest science, 70, 579-587.

Wang, W., Dalal, R., Moody, P. and Smith, C. (2003). Relationships of soil respiration to microbial biomass, substrate availability and clay content. Soil Biology and Biochemistry, 35, 273-284.

Warnock, D. D., Lehmann, J., Kuyper, T. W. and Rillig, M. C. (2007). Mycorrhizal responses to biochar in soil-concepts and mechanisms. Plant and Soil, 300, 9-20.

$\mathrm{Xu}$, G., Wei, L., Sun, J., Shao, H. and Chang, S. (2013). What is more important for enhancing nutrient bioavailability with biochar application into a sandy soil: Direct or indirect mechanism? Ecological Engineering, 52, 119-124.

Yao, Y., Gao, B., Zhang, M., Inyang, M. and Zimmerman, A. R. (2012). Effect of biochar amendment on sorption and leaching of nitrate, ammonium, and phosphate in a sandy soil. Chemosphere, 89, 14671471.

Zhang, A., Bian, R., Pan, G., Cui, L., Hussain, Q., Li, L., Zheng, J., Zheng, J., Zhang, X., Han, X. and YU, X. (2012). Effects of biochar amendment on soil quality, crop yield and greenhouse gas emission in a Chinese rice paddy: A field study of 2 consecutive rice growing 
Influence of Bio-char for Sustainable Agriculture

cycles. Field Crops Research, 127, 153-160.

Zheng, H., Wang, Z., Deng, X., Herbert, S. and Xing, B. (2013). Impacts of adding biochar on nitrogen retention and bioavailability in agricultural soil. Geoderma, 206, 32-39. 